RESEARCH ARTICLE

\title{
Indigenous Knowledge Systems in Environmental Governance in Canada
}

\author{
Deborah McGregor \\ Osgoode Hall Law School and Faculty of Environmental and Urban Change, York University
}

\begin{abstract}
This contribution addresses key issues around the application of Indigenous knowledge in contexts where such knowledge is neither generated nor held (academy, industry, governments, etc.). Effective models for the ethical incorporation of Indigenous knowledge into environmental governance in Canada have remained elusive despite decades of attempts. The predominant research paradigm of "incorporating" Indigenous knowledge into environmental governance is one of extraction by the external interests who seek to include specific aspects of such knowledge in their undertakings. This approach continues to fail because Indigenous knowledge exists as an integral component of Indigenous Knowledge Systems (IKS). It is often hollow and potentially damaging to consider any knowledge without understanding the societal systems and peoples that produced it. Indigenous knowledge is not just "knowledge" (a noun) but a way of life, something that must be lived (a verb) in order to be understood. Indigenous knowledge is inseparable from the people who hold and live this knowledge. Although government policy and legislation have evolved in attempts to treat Indigenous knowledge more holistically, the overriding paradigm of extraction remains essentially unchanged. Even the most recent frameworks will meet with limited success as a result. Appropriate and effective inclusion of Indigenous knowledge requires recognition of the systems that support it, which in turn necessitates support for Indigenous self-determination.
\end{abstract}

Keywords: Indigenous Knowledge Systems; Indigenous reconciliation; ethics protocols; environmental governance; self-determination

\section{Introduction}

There is no way to quantify a way of life, only a way to live it.

Winona LaDuke $(1999,132)$

Anishinaabe scholar/activist Winona LaDuke offered the above insight over two decades ago, yet her remark remains as relevant today as it was then. Her statement captures the impossibility of trying to package Indigenous knowledge (see "A Note on Terminology" in the box below) into forms considered "useful" for non-Indigenous enterprises without losing the original effectiveness and purpose of such knowledge. Removed from its original context, Indigenous knowledge invariably suffers from a loss and/or distortion of meaning, which can result in a variety of negative consequences.

This contribution is based on my more than three decades of work advocating for Indigenous knowledge/ Indigenous knowledge systems in Canada in my capacity as an Anishinaabe scholar and environmental professional working with Indigenous organizations, government agencies (particularly what was then Environment Canada), and academia. I hope these experiences will assist others who have faced (or will face) many of the same challenges I have in working to advance Indigenous self-determination.

This paper addresses key issues around the application of Indigenous knowledge in contexts where such knowledge is neither generated nor held (academy, industry, governments, ENGOs, the public, etc.). 


\section{A Note on Terminology}

The term Indigenous knowledge (or knowledges, if one is emphasizing the diversity of such knowledge), is abbreviated as IK, and has over time been variously referred to as traditional knowledge, traditional environmental knowledge, traditional ecological knowledge, or Aboriginal traditional knowledge, among other terms. The term is used in this paper in its broadest possible sense. That is, IK is knowledge that is an integral, inseparable feature of Indigenous societal systems (which I and others also call Indigenous Knowledge Systems, or IKS). While governments and other non-Indigenous agencies have also recently taken to using the Indigenous knowledge (IK) term, they are generally referring to a much more limited concept that sees IK as data and/or information that can be extracted and transferred from one context (Indigenous) to another (non-Indigenous). As this paper explains, this limited conception is counter-productive to the all-important task of Indigenous-non-Indigenous reconciliation.
Effective models for the ethical and respectful incorporation of IK into environmental governance in Canada have remained elusive despite decades of attempts. The predominant research paradigm of "incorporating" IK into environmental governance (or any other endeavour, for that matter) is one of extraction by governments, the academy, development proponents, ENGOs-all those external interests who seek to include IK in their undertakings.

Tensions remain regarding the conditions in which Indigenous nations and communities choose to share (or not share) their knowledge (McGregor 2014). My contribution here is inspired in part by my participation on a panel at the 2017 Congress of the Humanities and Social Sciences in Toronto, composed primarily of Indigenous scholars, which was convened to address the question, "As part of the broader processes of reconciliation, how can IKs be appropriately incorporated or considered in the academy?" The underlying challenge identified by the panel was that external institutions/agencies are not ready to respect IKS and Indigenous peoples. This was of course not what the panel organizers expected to hear. The question then remained: how can the broader movement for Indigenous-non-Indigenous reconciliation prepare external agencies to engage respectfully with IKS in a manner desired and required by Indigenous peoples?

\section{Indigenous Knowledge(s) vs. Indigenous Knowledge Systems}

I have given well over 150 presentations on the topic of Indigenous knowledge systems and why respect should be given to Indigenous peoples and their knowledge. During such presentations (usually panels), I am often allotted eight to ten minutes in which to describe the "utility" of Indigenous knowledge to primarily non-Indigenous audiences. In my presentations, I begin by sharing the following points:

- Indigenous knowledge(s) have existed for thousands of years. IKs are not new.

- Recognition of and interest in IKs by external interests is, in contrast, relatively recent.

- IKs can help us meet environmental challenges, as they have done for thousands of years.

- For this and related reasons, Indigenous knowledges are increasingly recognized at local through to international levels in agreements, conventions, legislation, policies, programs, and practices.

- Resistance to accepting Indigenous knowledges on par with other knowledges remains an ongoing challenge.

The increasing interest in IK, spurred on in part by a variety of international conferences and declarations such as those initiated by the United Nations, has resulted in the emergence of a now-recognized field of study (see McGregor 2000; McGregor 2005; McGregor 2014; McGregor 2020). The external interests involved in the field seem to be heavily focused on the knowledge of Indigenous peoples rather than on the well-being of the people themselves or of the systems that support the knowledge's generation, renewal, and transformation. When I am given a few more minutes to explain or describe IKS as part of the panels or presentations, I therefore proceed to the following points:

- Indigenous knowledge is embedded in systems supported by and in support of Indigenous societies. It is often hollow and potentially damaging to consider any knowledge without understanding the societal systems that produced, maintained, applied, and transmitted it.

- IKS represent more than just "knowledge" (as a noun); they represent a way of life, something that has to be lived (as a verb) in order to be known, understood, and practiced.

- IKS consider relationships not only among people but among all our relations, including all living things, the spirit world, our ancestors, and those yet to come. 
- All beings of Creation, including people, have relationships, knowledge, and responsibilities.

- IKS can exist outside the domain of humanity.

- Historical and ongoing colonialism, including genocidal practices, have disrupted and continue to pose significant challenges to the generation, innovation, transmission, and practice of IKS.

All this, I summarize, means that, at the most fundamental level, one cannot ever really "acquire" or "learn" Indigenous knowledge without having undergone similar experiences to those originally involved in acquiring/ generating, holding, and transmitting such knowledge.

These remarks are frequently upsetting to those unfamiliar with the field from an Indigenous perspective, particularly those hoping to simply extract some "useful" knowledge and apply it to their own endeavours. The inadequacy of the "extraction" approach quickly becomes all too apparent. For starters, and as indicated by the first point, Indigenous knowledge does not exist in isolation, but rather as an integral component of IKS-Indigenous Knowledge Systems. IK is conceptualized differently in Indigenous society; it is not just the dictionary definition of knowledge with Indigenous tacked on. Arabana scholar Professor Veronica Arbon conceptualizes Indigenous knowledges as "what we can see, which is tangible, but also that which is not tangible, or is invisible, in an event" $(2017,71)$. She adds that "Indigenous knowledges are really complex and we have got to work with and within them to know them and keep them alive" (2017, 71, italics added).

The term IKS, then, refers to the broader political, legal, economic, and cultural systems that enable the continued generation and renewal of Indigenous peoples to ensure their well-being (McGregor 2018). This seems to puzzle folks a great deal, as they do not relate to what I mean by systems until I explain that western knowledge is also generated as part of a broader political, economic, and educational system. Western knowledges, including the sciences, are frequently generated and transmitted through publicly funded post-secondary institutions by scientists, practitioners, researchers, and students as part of the formal education system. Funding, research, and educational priorities change, sometimes quite dramatically, depending on the government, politics, economics, and societal demands of the day. What educational programs are funded, who counts as the experts (their education, qualifications, etc.), and how expert knowledge is vetted (through peer-reviewed publications, conferences, etc.) are all highly political and determine what is taught and how. All of this and more comprises a system of producing knowledge. It would be inconceivable to confuse knowledge generated from a single research project or course taught with the education system as a whole.

A similar understanding applies to knowledges that are generated within Indigenous knowledge systems in a broader Indigenous society. IKS include how Indigenous peoples generate knowledge within their own legal and governance structures and protocols, including political, economic, social, and cultural systems. Indigenous peoples decide who their knowledge keepers and practitioners are and how the knowledge will be transmitted, transformed, protected, and governed to meet the challenges of the day. Indigenous knowledges are not just floating around untethered to broader Indigenous societal goals and aspirations.

I find that this message is neither what external interests want to hear nor in many cases are actually ready to hear. They remain committed to the notion that they can obtain what they need by somehow just learning to extract Indigenous knowledges from Indigenous peoples and their systems of knowledge.

\section{The Extraction Paradigm: Three Main Approaches}

To date, I have observed three main approaches to the extraction of knowledge from Indigenous peoples by non-Indigenous agencies. In the first approach, palatable or recognizable "bits" (often referred to as data or information) are extracted. Decades ago, Dr. Henry Lickers, former director of-and now scientific advisor for-the Mohawks of Akwesasne, described this as "the nuts and berries approach." All that scientists and researchers wanted to know was where Indigenous peoples picked berries and gathered nuts, so that they could then "document" such "knowledge" in maps and reports. In Dr. Lickers' view, there has been an outright refusal by external interests to recognize Indigenous knowledge as more than "data" or "information" to be utilized for the benefit of outside or external interests. For decades, Dr. Lickers (2021) has therefore insisted upon the recognition of what he terms "naturalized knowledge systems."

Over time, this extraction process has become more nuanced, with more categories and nomenclature created to address the various needs of external interests. For example, some scientists and resource managers now seek only "ecological" knowledge; thus, the concept of "Traditional Ecological Knowledge" (TEK) and methods of extracting it were developed. I still see this approach evident in the literature under the term "integration" of TEK and western science (Usher 2000; Verma et al. 2016). In this paradigm, data or information is extracted from Indigenous knowledge and subjected to categorization (e.g., water TEK, forest TEK, climate change TEK, wildlife TEK). In other words, proponents want only certain pieces or bits of relevant knowledge and not to bother with the aspects that give deeper ontological meaning, thus decontextualizing the knowledge in the process. Scholars in years past have called this "cherry picking" and the "scientization" 
of Indigenous knowledges (Stevenson 2005). In the realm of such practice, Indigenous knowledge systems are not recognized.

Due to Indigenous advocacy, a second approach has emerged in an attempt to develop ways of extracting knowledge from Indigenous peoples while (in theory anyway) treating the knowledge holistically (avoiding breaking it into categories and "manageable bits" for external consumption). This is what the Government of Canada is seeking to do through the development of its recently created Indigenous Knowledge Policy Framework (Government of Canada 2019) and guidance documents. As the framework states, "Indigenous Knowledge enables federal organizations to have a more complete understanding of Indigenous world views, Indigenous cultures, the environment, and the social, health and economic conditions of Indigenous peoples" (Government of Canada 2019, 2). At the same time, however, the framework relies upon a simplistic definition of Indigenous knowledge ("Indigenous knowledge means the Indigenous knowledge of the Indigenous peoples of Canada" [House of Commons 2018]) and mentioned nowhere are the legal, political, and governance systems of Indigenous peoples-the aspects that are seen as potentially challenging to the Canadian state's authority. Under this framework, Indigenous knowledge is still extracted from Indigenous people for external purposes, such as inclusion in the Impact Assessment Act.

The third approach recognizes that Indigenous knowledges exist within systems of knowledge and broader Indigenous society. To some extent this was recognized in Building Common Ground: A New Vision for Impact Assessment in Canada (2017), which stated that:

Recognition of and support for Indigenous laws and inherent jurisdiction should be built into [Impact Assessment] governance and processes. [Impact Assessment] should not be a process designed and imposed from afar; Indigenous Peoples should have the ability to adapt the process to reflect their own traditions, customs, law and aspirations. (29)

The expert panel that produced the Common Ground document, based on testimony heard from Indigenous peoples and the public on the then Canadian Environmental Assessment Act, stressed that Indigenous peoples must be part of the decision-making, thus reducing the need to extract Indigenous knowledge. In the end, however, Indigenous legal orders and governance were not reflected in the final Impact Assessment legislation and the resultant IK policy and guidance. In this instance, the opportunity existed for the implementation of a different paradigm based on knowledge exchange and shared decision-making, but this was rejected in favour of the decades-old status quo (Eckert et al. 2020).

If I have time remaining during my IKS presentations, I conclude with the following remarks:

- Given all of the above, the only appropriate and effective way for IKS to be "utilized" in environmental governance is to involve Indigenous peoples as nations, societies, and governments, with particular attention given to the holders/keepers and practitioners of IKS. It is simply neither appropriate nor constructive to try to "extract" Indigenous knowledge from Indigenous peoples.

- Indigenous peoples should be positioned as leaders in environmental protection, conservation, and assessment; not as "interest" groups to be "incorporated" or "included."

- Indigenous knowledge resides in the people, the community, the land (places); it may not be tangible or quantifiable in ways inherent to other knowledge systems (e.g., western science).

- The only way to appropriately understand IKS or IKs is to establish meaningful relationships with Indigenous peoples on their own terms.

Fundamental, then, from an Indigenous perspective, is that IK and IKS are inseparable from the people who hold and live this knowledge. I share Comanche-Nahua scholar Patrisia Gonzales' concern when she states that "I am most concerned with what happens as our TEK changes when it is taken out of the spaces and relationships over time that we have developed with our lands, our waters, our medicines" $(2020,85)$. She argues, as do others, that IKS is derived from the lands/waters/winds-the Earth itself. Disruptions to these connections/relationships have had devastating impacts on Indigenous peoples (Absolon 2010). We have been denied access to our knowledge keepers, including the natural world itself, and now find ourselves in the position of having to seek out our ancestral knowledges. As Anishinaabe scholar Kathy Absolon and the late Grandmother Josephine Mandamin have described it, we are in the process of "picking up one's bundles" (Absolon 2010, 80; Mandamin 2012, 14). Reacquiring, retaining, and revitalizing Indigenous languages accompanies these ongoing efforts (Chiblow 2020).

The challenges and opportunities facing Indigenous peoples in reclaiming their ancestral knowledge and languages is a critical topic. In this contribution, however, I wish to focus on the issues Indigenous communities face on a daily basis due to the attempted acquisition of TEK/IKS by external interests, as now 
mandated by federal law. Two areas of this discussion are presented in further detail below: extraction by external interests and innovations in respecting the integrity of IKS.

\section{Extraction by External Interests}

Indigenous knowledge is often treated as if it is only relevant when it can serve external interests. This approach is commonly referred to in the literature as the "utility" or "application" of Indigenous knowledge (or its constructed sub-categories) to conservation, environmental assessment, species recovery, wildlife management, or any field you care to name. Indigenous knowledge to date has been seen primarily by external agencies as having value and utility only when it serves these other purposes. In contrast, Indigenous (Potawatomi) scholar Kyle Whyte suggests that scientists and others should commit themselves to figuring how they will fit their knowledge into Indigenous governance systems if they truly expect effective and equitable knowledge exchange to take place (Whyte 2018).

Fortunately, the extraction approach is being challenged, due in part to the formal recognition of IKS in the 2007 United Nations Declaration on the Rights of Indigenous Peoples (UNDRIP). UNDRIP to an extent offers a framework for how external interests can support IKS, by laying out what is required to support Indigenous self-determination from political, economic, social, health, legal, cultural, and spiritual perspectives. Article 31 of UNDRIP states that:

1. Indigenous peoples have the right to maintain, control, protect and develop their cultural heritage, traditional knowledge and traditional cultural expressions, as well as the manifestations of their sciences, technologies and cultures, including human and genetic resources, seeds, medicines, knowledge of the properties of fauna and flora, oral traditions, literatures, designs, sports and traditional games and visual and performing arts. They also have the right to maintain, control, protect and develop their intellectual property over such cultural heritage, traditional knowledge, and traditional cultural expressions.

2. In conjunction with indigenous peoples, States shall take effective measures to recognize and protect the exercise of these rights. (United Nations General Assembly 2007)

These statements mean that the Canadian state has an obligation to support Indigenous peoples in developing "measures" to protect Indigenous knowledges and systems of knowledge. Many Indigenous groups have nonetheless found it necessary, in response to ongoing efforts by external interests to essentially exploit Indigenous peoples for their knowledge, to develop IKS protocols to protect their knowledge from such exploitation. Examples include the Maliseet Nation Traditional Knowledge Protocol; the Mi'kmaq Ecological Knowledge Study Protocol; the Guidelines for Considering Traditional Knowledges in Climate Change Initiatives; and the First Nations Ethics Guide on Research and Aboriginal Traditional Knowledge.

Overall, the exploitative approaches taken by external interests have failed to protect IKS or Indigenous peoples and their rights (United Nations General Assembly 2017). As more and more people are realizing, the protection of Indigenous peoples' rights and the planet's health go hand in hand. Recent high-profile reports from the United Nations and related expert panels clearly demonstrate how global society is continuing to fail to protect the planet's diverse ecosystems, including the most vulnerable peoples who inhabit them (IPBES 2019; IPCC 2018). Whyte (2020) characterizes this failure to make inroads into the ongoing ecological and climate crisis as an astonishing failure to attend to just relationships with Indigenous peoples.

\section{Innovations in Respecting the Integrity of IKS}

This ongoing exploitation brings me to my second point here: researchers and practitioners alike continue to struggle with devising models or approaches for enabling Indigenous and western knowledges to interact with each other in a manner that respects the integrity of IKS and Indigenous peoples. Some models that have been developed and that draw on Indigenous approaches to knowledge-sharing include: Two-Eyed Seeing (or Etuaptmumk in Mi'kmaq; see Abu, Reed, and Jardine 2019; Reid et al. 2020), braiding knowledge systems (Kimmerer 2013), weaving knowledge systems (Whyte, Brewer, and Johnson 2016), the Two-Row Wampum (Latulippe 2015; Ransom and Ettenger 2001), and knowledge co-production (Latulippe and Kneck 2020). These approaches seek to move away from the "integration" or "assimilation" of Indigenous knowledge into western knowledge frameworks and towards processes that aim to respect Indigenous knowledge on its own terms. There remains significant room for improvement in how these types of models are applied in practice, as it continues to be extremely difficult to escape the dominance of western systems entirely and to have all parties begin to view Indigenous systems as equally valid. Still, the intent is clear: when "integrative" approaches are abandoned in favour of Indigenous conceptions of the interplay of knowledge systems, the 
metaphors and models thus arising (braiding, weaving, etc.) should retain the integrity of IKS and be cogenerative in nature rather than assimilative. Implicit in any initiative that maintains the integrity of IKS is the recognition of Indigenous systems of law and governance.

\section{IKS and Western Science Collaboration in Canada: A Federal Policy and Legislation Update}

Interest in IKS in Canada continues to evolve, as evidenced by ongoing environmental reform that has resulted in formal recognition of IK in recently modernized or enacted legislation (e.g., Fisheries Act, Impact Assessment Act). Despite the persistent tension between Indigenous advocacy for the strengthening of IKS in environmental management regimes and the need to protect Indigenous knowledges from misuse, misrepresentation, or appropriation, recognition of Indigenous knowledge in a variety of settings has substantially increased. This recognition has tended primarily to appear in science-based legislation and departments such as Environment and Climate Change Canada, the Department of Fisheries and Oceans, and Parks Canada, and thus the inevitable IKS/western science binary emerges yet again.

References to Indigenous knowledge (labelled by the federal government until recently as Aboriginal Traditional Knowledge or ATK) have formed part of Canadian legislation since 1999, but have done so without an effective policy or meaningful governance framework for implementation. Indigenous knowledges were "dealt with" on an ad-hoc basis at the discretion of managers, scientists, and others from the relevant agencies. Only two public Indigenous knowledge guidance initiatives have been developed over the past decade to address this IKS-related policy vacuum. The first was the 2017 Aboriginal Traditional Knowledge: Process and Protocols Guidelines document, created under the Species at Risk Act for COSEWIC (the Committee on the Status of Endangered Wildlife in Canada) to assist in the process of assessing species at risk. The second was the "Considering Aboriginal Traditional Knowledge in Environmental Assessments Conducted Under the Canadian Environmental Assessment Act, 2012" paper (Impact Assessment Agency of Canada 2015), which was intended to provide guidance on environmental assessment under the former Canadian Environmental Assessment Act. Having worked in a federal science department dispensing advice on Indigenous knowledge in conservation, protection, and assessment programs, I find these guidelines to have been wholly inadequate to address the depth and breadth of Indigenous knowledge work required.

From the outset, it must be recognized once again that there is a substantial difference between considering Indigenous knowledge as a packageable and transferrable item and recognizing such knowledge instead as an integral and inseparable component of Indigenous knowledge systems. These systems in turn emerge from worldviews held by Indigenous peoples, the recognition of which leads us to the understanding that Indigenous knowledge and IKS are themselves inseparable from the people who live that knowledge and those systems on a daily basis and who have done so for thousands of years. By continuing to focus on incorporating Indigenous knowledge rather than on collaborating with Indigenous peoples to fully recognize IKS, governments and other external actors are explicitly excluding the broader systems of knowledge since these may well directly challenge the purpose and intent of the very legislation within which attempts at compartmentalized Indigenous knowledge currently find expression. In short, Indigenous knowledge "incorporation" serves federal government and other external agency agendas, but not Indigenous self-determination. This circumstance indicates to me that, despite touted "advances" in the incorporation or consideration of Indigenous knowledge in federal legislation such as the Impact Assessment Act and the Fisheries Act, the authorities behind such legislation either do not understand the Indigenous knowledge/IKS discrepancy or, worse (and more likely), choose not to "go there" due to the implications of formally acknowledging Indigenous legal, political, and governance systems and what that might mean for Canadian environmental governance. Indigenous organizations have predictably levelled significant criticism at the new legislation, warning that the reported "innovations" contained therein continue to undermine Indigenous laws, knowledge, self-determination, and sovereignty.

In 2019, the Government of Canada, as part of the larger reconciliation agenda and promises made during the environmental reform process, commenced public engagement to obtain input into how Indigenous knowledge should be considered in regulatory frameworks. A discussion paper titled Indigenous Knowledge Policy Framework for Proposed Project Reviews and Regulatory Decisions (Government of Canada 2019) was released for general consideration as part of the public input process. The policy framework document stated that:

The policy framework will be developed in partnership with Indigenous peoples, with further input being sought from Indigenous individuals, governments, communities and organizations through various meetings and workshops on Indigenous knowledge.... 
Indigenous knowledge has made, and continues to make, valuable contributions to environmental, regulatory, and other processes across the country. Indigenous knowledge has also been the focus of growing international discourse. In recognition of the unique perspectives and value of Indigenous knowledge, governments across the world have integrated Indigenous knowledge into decision-making. (Government of Canada 2019, 2)

\section{The paper itself sought to}

initiate a discussion and seek input from Indigenous peoples, stakeholders, provinces, territories and the public on principles, best practices and other elements that will inform the development of an Indigenous Knowledge Policy Framework for proposed project reviews and regulatory decisions. (Government of Canada 2019, 2)

Despite the government claims with respect to valuing Indigenous knowledge, the public engagement strategy was criticized by Indigenous peoples because they did not feel it was appropriate for the "public" (including development proponents, industry representatives, etc.) to have a say in how Indigenous knowledges would be considered in the new legislation. Indigenous peoples see such knowledge as being under their own jurisdiction. A public review process on the topic of Indigenous knowledge incorporation thus flew in the face of the need to respect Indigenous peoples' authority, autonomy, and jurisdiction (as detailed in UNDRIP) over decisions concerning their own knowledge. This was, of course, not seen by Indigenous peoples as a promising start and was in direct contravention of UNDRIP and basic principles of self-determination.

It is my view that Indigenous communities can count on neither the governments of Canada nor other non-Indigenous agencies to protect Indigenous knowledge and "utilize" it wisely within their own environmental governance frameworks. If IKS are to be protected at all, Indigenous communities must instead, at least as a first step, be supported in their efforts to codify their own knowledge protection systems and knowledge sharing protocols and to manage external interests that seek to extract their knowledge from them.

This message hit home again recently when I participated in a research initiative by the newly minted federal Impact Assessment Agency. I and the other participants had been asked to determine better ways to consider Indigenous knowledges in Impact Assessment. The question posed concerned (yet again) how to "integrate" Indigenous knowledges into these non-Indigenous public review and regulatory processes. My initial comments to the consultants tasked with this work consisted essentially of, "You still are not asking the right questions" and "We are back where we were decades ago." Fundamentally, we, as Indigenous peoples, continue to be asked how to "fit" Indigenous knowledge into externally derived agendas. I also participate on an advisory committee engaged in the same process for the modernized Fisheries Act. In this setting, Indigenous peoples repeatedly raise concerns about the absence of respect for the broader IK systems, including legal and governance systems, in these "engagements."

\section{Final Remarks}

One of the gravest omissions from the current approach to the development of an appropriate IKS/western science collaborative framework is the refusal to acknowledge the broader colonial, genocidal, and racist context within which all this work takes place. The Indigenous Knowledge Policy Framework and guidance documents, although couched in the language of reconciliation, have failed to explicitly address historical and ongoing colonialism and to take seriously the Calls to Action and Calls to Justice of the Truth and Reconciliation Commission (2015) and the National Inquiry into Missing and Murdered Indigenous Women and Girls (NIMMIWG) in 2019.

It is fair to ask me at this point, as some people have done, why I continue to be so engaged in this issue when I remain so skeptical of the motivation and direction of the processes repeatedly set in motion by external interests. My answer in large part is that I take seriously my obligations and responsibilities to those who have asked me, on behalf of Indigenous governments and organizations, to continue to advocate for Indigenous knowledge systems and Indigenous peoples as a whole. In part, though, it is also because I do see some hope for change, led by Indigenous peoples. Though overall progress can seem excruciatingly slow, there is at least more talk about these issues now than there has ever been during my decades-long career. Collectively, we have moved, at least in terms of language, beyond the "nuts and berries" approach of simply trying to "capture" or "gather" Indigenous knowledge from Indigenous peoples. I remain committed to seeing how much of the positive talk around reconciliation, for example, can be turned into substantive action. 
It is not a comfortable space in which to work (and much of the time I am making others feel uncomfortable as well!), but I continue to advocate as requested nonetheless.

I have now provided some insights into the Indigenous knowledge policy and governance framework developed at the federal level in Canada. It is my intention in upcoming work to show that these recent IK policies and processes, although on the one hand ostensibly advocated for by Indigenous peoples, will continue to fail to enact the real change required to respect Indigenous peoples, their rights and knowledges, and, unfortunately, ecosystem health as well. This failure is inevitable because these processes are still not designed with the intent of establishing mutually beneficial partnerships with Indigenous peoples on a nation-to-nation basis. Instead, they are still very much ensnared in the idea of "extracting" those "bits" of Indigenous knowledges that western systems and decision-makers find palatable to incorporate or integrate into their existing frameworks, when IKs are considered at all. These processes continue to exclude the systems and context that generate and govern IKS. Attempts to mobilize Indigenous knowledges remain focused on serving the economic and prosperity goals of Canadian society and not the visions, goals, and aspirations of Indigenous nations. If this approach is to change, we must look to Indigenous perspectives on the concept of reconciliation. If we return to Kyle Whyte's diagnosis of the climate/ecological crisis as one of failed relationships, then the broader political context matters, and how reconciliation is advanced will either assist in this matter or hinder it.

In 2015, the Truth and Reconciliation Commission (TRC) launched a new chapter in Indigenous-state relationships in Canada. The TRC identified ten principles to guide reconciliation efforts, in which Indigenous knowledge systems are explicitly recognized as being vital to the process. The $\operatorname{TRC}(2015,4)$ asserts that "Supporting Aboriginal peoples' cultural revitalization and integrating Indigenous knowledge systems, oral histories, laws, protocols, and connections to the land into the reconciliation process are essential."

In response to the question posed to the Congress panel a few years ago regarding how we, as Indigenous scholars and practitioners, could help incorporate IK into the work of the academy, panel members countered with their own question, which was: "Are you ready for IKS?" It seems that in the area of environmental governance, the answer is: "Not yet." It is time to see Indigenous peoples leading these types of initiatives and asking the appropriate questions. Then perhaps we will begin to see the change that is so urgently needed.

\section{References}

Absolon, Kathy. 2010. "Indigenous Wholistic Theory: A Knowledge Set for Practice." First Peoples Child \& Family Review 5 (2): 74-87. https://fpcfr.com/index.php/FPCFR/article/view/95. Archived at: https:// perma.cc/HEU7-FT72.

Abu, Razak, Maureen G. Reed, and Timothy D. Jardine. 2019. “Using Two-Eyed Seeing to Bridge Western Science and Indigenous Knowledge Systems and Understand Long-Term Change in the Saskatchewan River Delta, Canada." International Journal of Water Resources Development 36 (5): 757-76. https://doi. org/10.1080/07900627.2018.1558050.

Arbon, Veronica. 2017. "Indigenous Knowledges: Growing Knowledges Through Research." In Indigenous Knowledges: Proceedings of the Water Sustainability and Wild Fire Mitigation Symposia, 2012 and 2013, edited by Suzi Hutchings and Anne Morrison, 63-77. Underdale, SA: University of South Australia.

Canadian Environmental Assessment Agency. 2017. "Building Common Ground: A New Vision for Impact Assessment in Canada." https://www.canada.ca/en/services/environment/conservation/assessments/ environmental-reviews/environmental-assessment-processes/building-common-ground.html. Archived at: https://perma.cc/A9UK-WJD8.

Committee on the Status of Endangered Wildlife in Canada (COSEWIC). 2017. "Aboriginal Traditional Knowledge: Process and Protocols Guidelines." COSEWIC Secretariat, Canadian Wildlife Service. Ottawa, ON. https://cosewic.ca/index.php/en-ca/assessment-process/atk-guidelines.html. Archived at: https:// perma.cc/WX8J-3782.

Eckert, Lauren E., Nick XEMFOLTW_Claxton, Cameron Owens, Anna Johnston, Natalie C. Ban, Faisal Moola, and Chris T. Darimont. 2020. "Indigenous Knowledge and Federal Environmental Assessments in Canada: Applying Past Lessons to the 2019 Impact Assessment Act." FACETS 5: 67-90. https://doi.org/10.1139/ facets-2019-0039.

Gonzales, Patrisia. 2020. "Water-Womb-Land Cosmologic: Protocols for Traditional Ecological Knowledge." Ecopsychology 12 (2): 84-90. https://doi.org/10.1089/eco.2019.0030.

Government of Canada. 2019. Discussion Paper: Indigenous Knowledge Policy Framework for Proposed Project Reviews and Regulatory Decisions. https://www.canada.ca/content/dam/themes/environment/conservation/environmental-reviews/ik-discussion-paper-en.pdf. Archived at: https://perma.cc/R6SS-622Z. 
House of Commons. 2018. Bill C-69. An Act to enact the Impact Assessment Act and the Canadian Energy Regulator Act, to amend the Navigation Protection Act and to make consequential amendments to other Acts. As passed by the House of Commons, June 20, 2018. https://www.parl.ca/DocumentViewer/ en/42-1/bill/C-69/third-reading.

Impact Assessment Agency of Canada. 2015. "Considering Aboriginal Traditional Knowledge in Environmental Assessments Conducted Under the Canadian Environmental Assessment Act, 2012." https://www.canada. $\mathrm{ca} /$ en/impact-assessment-agency/services/policy-guidance/considering-aboriginal-traditional-knowledge-environmental-assessments-conducted-under-canadian-environmental-assessment-act-2012.html. Archived at: https://perma.cc/5X4F-THMH.

IPBES. 2019. Summary for Policymakers of the Global Assessment Report on Biodiversity and Ecosystem Services of the Intergovernmental Science-Policy Platform on Biodiversity and Ecosystem Services. Edited by S. Díaz, J. Settele, E. S. Brondízio, H. T. Ngo, M. Guèze, J. Agard, A. Arneth, P. Balvanera, K. A. Brauman, S. H. M. Butchart, K. M. A. Chan, L. A. Garibaldi, K. Ichii, J. Liu, S. M. Subramanian, G. F. Midgley, P. Miloslavich, Z. Molnár, D. Obura, A. Pfaff, S. Polasky, A. Purvis, J. Razzaque, B. Reyers, R. Roy Chowdhury, Y. J. Shin, I. J. Visseren-Hamakers, K. J. Willis, and C. N. Zayas. Bonn: IPBES Secretariat. https://ipbes.net/sites/default/ files/2020-02/ipbes_global_assessment_report_summary_for_policymakers_en.pdf. Archived at: https://perma.cc/3KYR-SX6K.

IPCC. 2018. "Summary for Policymakers." In: Global Warming of $1.5^{\circ} \mathrm{C}$. An IPCC Special Report on the Impacts of Global Warming of $1.5^{\circ} \mathrm{C}$ above Pre-Industrial Levels and Related Global Greenhouse Gas Emission Pathways, in the Context of Strengthening the Global Response to the Threat of Climate Change, Sustainable Development, and Efforts to Eradicate Poverty. Edited by Masson-Delmotte, V., P. Zhai, H.-O. Pörtner, D. Roberts, J. Skea, P. R. Shukla, A. Pirani, W. Moufouma-Okia, C. Péan, R. Pidcock, S. Connors, J. B. R. Matthews, Y. Chen, X. Zhou, M.I. Gomis, E. Lonnoy, T. Maycock, M. Tignor, and T. Waterfield. https://www. ipcc.ch/site/assets/uploads/sites/2/2019/05/SR15_SPM_version_report_LR.pdf. Archived at: https:// perma.cc/4KT2-PD3B.

Kimmerer, Robin Wall. 2013. Braiding Sweetgrass: Indigenous Wisdom, Scientific Knowledge and the Teachings of Plants. Minneapolis, MN: Milkweed Editions.

LaDuke, Winona. 1999. All Our Relations: Native Struggles for Land and Life. Cambridge, MA: South End Press.

Latulippe, Nicole. 2015. "Bridging Parallel Rows: Epistemic Difference and Relational Accountability in Cross-Cultural Research." The International Indigenous Policy Journal6 (2): i-17. https://doi.org/10.18584/ iipj.2015.6.2.7.

Latulippe, Nicole, and Nicole Klenk. 2020. "Making Room and Moving Over: Knowledge Co-Production, Indigenous Knowledge Sovereignty and the Politics of Global Environmental Change Decision-Making." In "Advancing the Science of Actionable Knowledge for Sustainability," edited by James C. Arnott, Katharine J. Mach, and Gabrielle Wong-Parodi, special issue, Current Opinion in Environmental Sustainability 42 (February): 7-14. https://doi.org/10.1016/j.cosust.2019.10.010.

Lickers, Henry. 2021. "A Letter from Henry Lickers." January 18, 2021. International Joint Commission. https://ijc.org/en/letter-henry-lickers. Archived at: https://perma.cc/92E4-4CUF.

Mandamin, Josephine. 2012. "N'guh izhi chigaye, nibi onji: I Will Do It for the Water." In Anishinaabewin NIIZH: Culture, Movements, Critical Moments. Edited by Alan Corbiere, Deborah McGregor, and Crystal Migwans. M'Chigeeng, ON: Ojibway Cultural Foundation.

McGregor, Deborah. 2000. "The State of Traditional Ecological Knowledge Research in Canada: A Critique of Current Theory and Practice." In Expressions in Canadian Native Studies, edited by Ron F. Laliberte, Priscilla Settee, James B. Waldram, Rob Innes, Brenda Macdougall, Lesley McBain, and F. Laurie Barron, 436-58. Saskatoon, SK: University Extension Press.

McGregor, Deborah. 2005. “Traditional Ecological Knowledge: An Anishnabe Woman's Perspective." Atlantis: Critical Studies in Gender, Culture, and Social Justice 29 (2): 103-9. https://journals.msvu.ca/index.php/ atlantis/article/view/1057/1014. Archived at: https://perma.cc/EFY5-G2RN.

McGregor, Deborah. 2014. "Lessons for Collaboration Involving Traditional Knowledge and Environmental Governance in Ontario, Canada." AlterNative: An International Journal of Indigenous Peoples 10 (4): 340-53. https://doi.org/10.1177/117718011401000403.

McGregor, Deborah. 2018. "Indigenous Environmental Justice, Knowledge and Law." Kalfou: A Journal of Comparative and Relational Ethnic Studies 5 (2): 279-96. https://doi.org/10.15367/kf.v5i2.213.

McGregor, Deborah. 2020. "Mother Earth." Earth 2020: An Insider's Guide to a Rapidly Changing Planet, edited by Philippe Tortell, 133-39. Cambridge: Open Book Publishers. https://doi.org/10.11647/OBP.0193.

Ransom, James W., and Kreg T. Ettenger. 2001. "'Polishing the Kaswentha': A Haudenosaunee View of Environmental Cooperation." Environmental Science \& Policy 4 (4): 219-28. https://doi.org/10.1016/ S1462-9011(01)00027-2. 
Reclaiming Power and Place: The Final Report of the National Inquiry into Missing and Murdered Indigenous Women and Girls. 2019. https://www.mmiwg-ffada.ca/final-report/. Archived at: https://perma. cc/7CXP-BZQ9.

Reid, Andrea J., Lauren E. Eckert, John-Francis Lane, Nathan Young, Scott G. Hinch, Chris T. Darimont, Steven J. Cooke, Natalie C. Ban, and Albert Marshall. 2021. “Two-Eyed Seeing': An Indigenous Framework to Transform Fisheries Research and Management." Fish and Fisheries 22 (2): 243-61. https://doi. org/10.1111/faf.12516.

Stevenson, Marc G. 2005. Traditional Knowledge and Sustainable Forest Management. Edmonton, AB: Sustainable Forest Management Network. https://era.library.ualberta.ca/items/586763c3-2edd-40dd8ada-eb4ba3b4adf0/view/dd8d25db-29e0-4555-8add-106b895c8008/SR_200405stevensonmtrad_ en.pdf. Archived at: https://perma.cc/P8FH-52H5.

Truth and Reconciliation Commission of Canada. 2015. What We Have Learned: Principles of Truth and Reconciliation. Report of the Truth and Reconciliation Commission. https://ehprnh2mwo3.exactdn.com/ wp-content/uploads/2021/01/Principles_English_Web.pdf. Archived at: https://perma.cc/E3CG-ENTY.

United Nations General Assembly. 2007. Resolution 61/295. United Nations Declaration on the Rights of Indigenous Peoples. https://www.un.org/esa/socdev/unpfii/documents/DRIPS_en.pdf. Archived at: https://perma.cc/98NH-SAUG.

United Nations General Assembly. 2017. Report of the Special Rapporteur of the Human Rights Council on the Rights of Indigenous Peoples. https://undocs.org/A/72/186. Archived at: https://perma.cc/8QK4-2KV2.

Usher, Peter J. 2000. "Traditional Ecological Knowledge in Environmental Assessment and Management." Arctic 53 (2): 183-93. https://link.gale.com/apps/doc/A30033448/CPI?u=uvictoria\&sid=CPI\&xid= a8a1c271. Archived at: https://perma.cc/CP5B-7X7C.

Verma, Priya, Karen Vaughan, Kathleen Martin, Elvira Pulitano, James Garrett, and Douglas D. Piirto. 2016. "Integrating Indigenous Knowledge and Western Science into Forestry, Natural Resources, and Environmental Programs." Journal of Forestry 114 (6): 648-55. https://doi.org/10.5849/jof.15-090.

Whyte, Kyle. 2018. "What Do Indigenous Knowledges Do for Indigenous Peoples." In Traditional Ecological Knowledge: Learning From Indigenous Practices for Environmental Sustainability, edited by Melissa K. Nelson and Daniel Shilling, 57-81. https://doi.org/10.1017/9781108552998.005.

Whyte, Kyle. 2020. "Too Late for Indigenous Climate Justice: Ecological and Relational Tipping Points." WIREs Climate Change 11 (1): e603. https://doi.org/10.1002/wcc.603.

Whyte, Kyle Powys, Joseph P. Brewer II, and Jay T. Johnson. 2016. "Weaving Indigenous Science, Protocols and Sustainability Science." Sustainability Science 11: 25-32. https://doi.org/10.1007/s 11625-015-0296-6.

How to cite this article: McGregor, Deborah. 2021. Indigenous Knowledge Systems in Environmental Governance in Canada. KULA: Knowledge Creation, Dissemination, and Preservation Studies 5(1). https://doi. $\operatorname{org} / 10.18357 /$ kula.148

Submitted: 13 July 2020 Accepted: 27 January $2021 \quad$ Published: 22 June 2021

Copyright: @ 2021 The Author(s). This is an open-access article distributed under the terms of the Creative Commons Attribution 4.0 International License (CC-BY 4.0), which permits unrestricted use, distribution, and reproduction in any medium, provided the original author and source are credited. See http:// creativecommons.org/licenses/by/4.0/. 